\title{
Usefulness of saline infusion sonohysterography and feeding artery imaging in endometrial polyp diagnosis
}

\author{
Marcin Anioł, Grażyna Dec, Katarzyna Wojda, Piotr Sieroszewski \\ Department of Fetal Medicine and Gynecology, First Chair of Gynecology and Obstetrics, Medical University of Lodz, Poland
}

\begin{abstract}
Objectives: The aim of this study was to assess the usefulness of sonohysterography with feeding artery visualization using transvaginal sonography to diagnose endometrial polyps.

Material and methods: We conducted an observational study of 60 perimenopausal patients referred to the Department of Fetal Medicine and Gynaecology, Medical University of Lodz with abnormal uterine bleeding or suspicion of endometrial pathology based on sonography scan. In all 60 patients transvaginal sonography scan showed a possibility of an endometrial polyp. Of these, 46 underwent saline infusion sonohysterography with sonography visualization of a feeding artery. Pathological examination was performed on material collected during hysteroscopy.

Results: Sonography detection of endometrial polyp based on feeding artery visualization had a $40 \%$ sensitivity, whereas sonohysterographic polyp detection had a sensitivity of $75 \%$ and a specificity of $100 \%$. The positive and negative predictive values of saline infusion sonohysterography in diagnosing endometrial polyps were estimated at $75 \%$ and $72 \%(95 \% \mathrm{Cl}: 52-86 \%)$, respectively. The combination of sonohysterography and feeding artery imaging in transvaginal sonography was $84 \%$ sensitive and $95 \%$ specific in detecting endometrial polyps. The positive and negative predictive values were: $P P V=96 \%$ and NPV $=89 \%$.

Conclusion: Saline infusion sonohysterography with feeding artery visualization may become a standard method in the diagnostics of endometrial polyps in perimenopausal women.
\end{abstract}

Key words: sonography, endometrial polyp, sonohysterography

Ginekologia Polska 2017; 88, 6: 285-288

\section{INTRODUCTION}

Endometrial polyps are relatively common, occurring in $10 \%$ to $40 \%$ of all women. They are detected in $1 \%$ to $12 \%$ of asymptomatic patients during routine transvaginal sonography investigation [1]. In our clinical practice, we diagnosed endometrial polyps in $32 \%$ of women treated for infertility who qualified for in vitro fertilization. The incidence of precancerous and cancerous transformation is low in these polyps [1, 2]. According to recent reports, the percentage polyps that are malignant varies from $0.8 \%$ to $8 \%$ among postmenopausal patients with concomitant abnormal uterine bleeding [3-5].

A useful method of endometrial polyp detection is saline infusion sonohysterography (SIS), which is a combination of transvaginal sonography with simultaneous saline infusion into the uterine cavity. This technique allows further assess- ment of the uterine cavity during sonography examination $[5,6]$. According to the authors'knowledge, presented combination haven't been analyzed widely in the literature so far.

If an endometrial polyp is suspected, another diagnostic tool is preliminary verification using color Doppler to show a spiral artery penetrating the polyp as its feeding artery [7].

\section{OBJECTIVES}

The aim of this study was to assess the usefulness of saline infusion sonohysterography combined with feeding artery visualization to diagnose endometrial polyps.

\section{MATERIAL AND METHODS}

The study was conducted at the Department of Fetal Medicine and Gynecology, Medical University of Lodz 


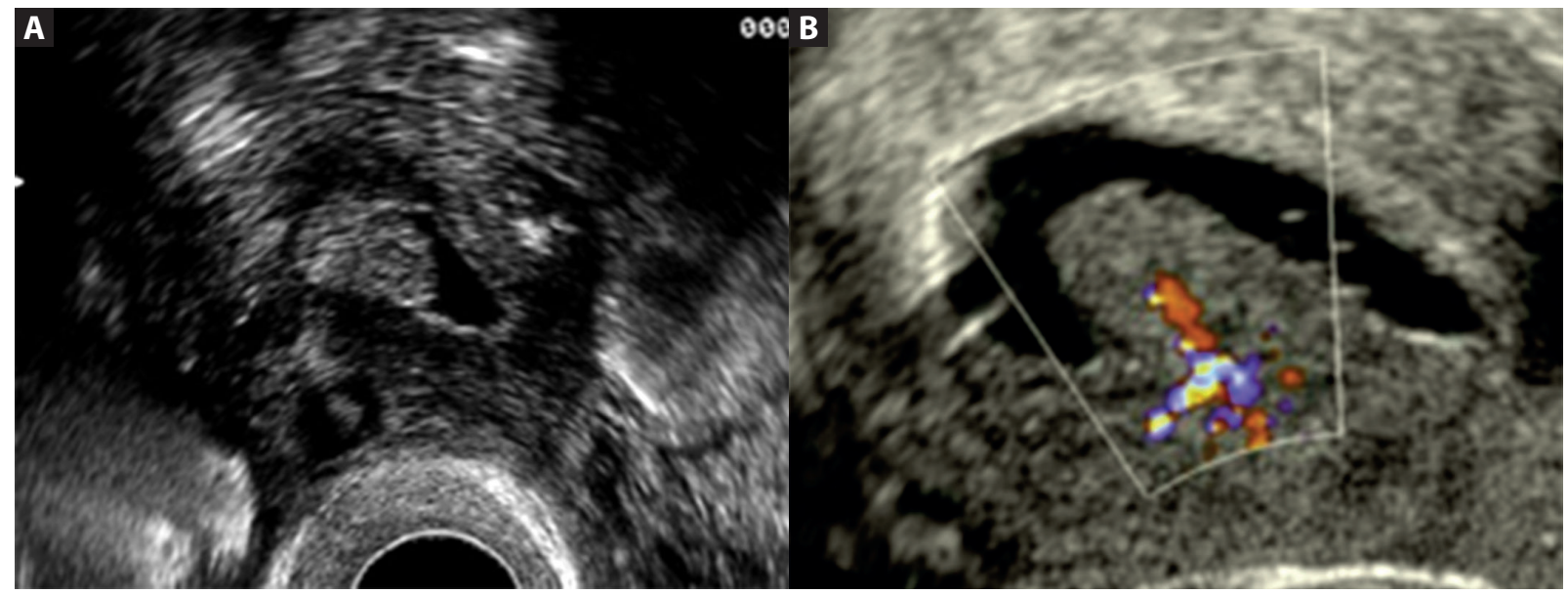

Figure 1A. Endometrial polyp and fluid in endometrial cavity visualised by transvaginal ultrasound; B. Polyp with feeding artery visualised by color Doppler sonography

from 2010 to 2012. The prospective study protocol was approved by the Bioethics Committee of the Medical University of Lodz (No. RNN/140/07/KE). All patients signed written informed consent. We included in the investigation 60 perimenopausal and postmenopausal patients with suspected endometrial polyps based on earlier transvaginal sonographys performed using a Philips M2540A scanner with a 5 to $9 \mathrm{MHz}$ frequency endovaginal transducer. During transvaginal sonography we focused on endometrial features as thickness, echogenicity, border between the endometrium and myometrium, visualization of the central echo, presence of a hypoechoic border, and presence of fluid in the uterine. We attempted to show the feeding artery by using the color and power Doppler.

Possible structural endometrial abnormalities were visualized and recorded in all 60 patients, including character and topography, followed by identification of the feeding artery using color Doppler.

To verify sonography-based diagnosis, endometrial biopsy was performed. After performing transvaginal sonography the saline infusion sonohysterography (SIS) combined with feeding artery visualization (FA) was performed in selected 46 patients (Figures 1 and 2). The exclusion criteria were: 1) vaginal inflammation, 2) presence of fluid in the uterine cavity or a very thick endometrium with blurred endometrium-myometrium borders, 3) receipt of hormone replacement therapy or tamoxifen, 4) lack of informed consent, or 5) technical difficulty in introducing a catheter into the uterine cavity. The saline infusion sonohysterography was performed after routine transvaginal sonography using the same sonography device.

Data were analyzed using STATISTICA 9.0 PL software and Vassar Stats website (http://vassarstats.net/).

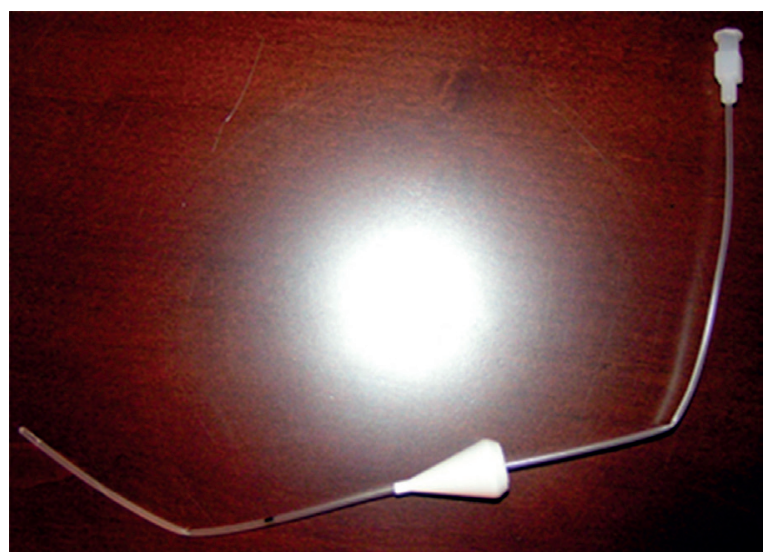

Figure 2. Catheter used in the saline infusion hysterosonography

\section{RESULTS}

Following a final pathological verification, endometrial polyps were confirmed in 28 patients, endometrial hyperplasia in 11 patients, submucous myoma in 10 patients, and no endometrial pathology was found in 11 patients.

An endometrial feeding artery was identified on sonography in 13 patients (21.6\%). A feeding artery was identified in 11 of 28 patients (39.3\%) for whom an endometrial polyp was pathologically confirmed. Although no feeding artery was detected by sonography in 17 patients (60.7\%) with pathologically confirmed endometrial polyps, a significant relationship was noted between sonography observed feeding arteries and pathological confirmation of endometrial polyps (Fisher's Test with Freeman-Halton correction for other than $2 \times 2$ tables, $\mathrm{p}=0.025$; Table 1 ). Among 32 women with other endometrial pathology only 2 patients had endometrial feeding arteries (6.2\%). Sonography polyp detection based on feeding artery presence was characterised by $40 \%$ sensitiv- 


\begin{tabular}{|c|c|c|}
\hline $\begin{array}{l}\text { Histopathological } \\
\text { diagnosis }\end{array}$ & $\begin{array}{l}\text { No feeding } \\
\text { artery present }\end{array}$ & $\begin{array}{c}\text { Feeding } \\
\text { artery present }\end{array}$ \\
\hline Polyp & $17(60.7 \%)$ & $11(39.3 \%)$ \\
\hline Hyperplasia & $10(90.9 \%)$ & $1(9.1 \%)$ \\
\hline Myoma & $10(100.0 \%)$ & $0(0.0 \%)$ \\
\hline Free from pathology & $10(90.9 \%)$ & $1(9.1 \%)$ \\
\hline Total & 47 (78.3\%) & 13 (21.6\%) \\
\hline
\end{tabular}

ity (95\% Cl: $24-56 \%)$ and 94\% specificity (95\% Cl: 80-98\%) with a positive predictive value of $84 \%(95 \% \mathrm{Cl}: 58-96 \%)$ and a negative predictive value of $63 \%$ (95\% Cl: $50-76 \%$ ).

Among 46 patients who were qualified for saline infusion sonohysterography a submucous myoma was found in 8 patients (17\%), endometrial polyp was found in 21 patients (46\%), and a thickened endometrium without focal abnormalities was found in 17 patients (37\%). All diagnoses made after SIS were also confirmed by pathological investigations. The Cohen's kappa coefficient of agreement was 1.00 (95\% Cl: 1.00-1.00). Pathologically confirmed polyp was diagnosed in 28 patients. Twenty one of them had polyp visible in sonohysterography. The sensitivity of sonohysterography in diagnosing endometrial polyps was $75 \%(95 \% \mathrm{Cl}$ : $57-87 \%)$ and specificity was $100 \%$ (95\% Cl: $100-100 \%)$. The positive and negative predictive values of SIS in diagnosing endometrial polyps were estimated at: PPV $=75 \%(95 \% \mathrm{Cl}$ : $57-87 \%)$ and NPV $=72 \%$ (95\% Cl: 52-86\%), respectively.

The combination of saline infusion sonohysterography with feeding artery imaging seemed to be the most useful test in detecting endometrial polyps. Among 28 patients with pathologically confirmed polyps, the SIS + FA result was negative in only 2 cases (7.1\%). The SIS + FA diagnostic method was associated with $84 \%$ sensitivity $(95 \% \mathrm{Cl}$ : 77-98\%) and 95\% specificity (95\% Cl: 74-99\%). The positive and negative predictive values for this extended imaging diagnosis were: PPV = 96\% (95\% Cl: 82-99\%) and NPV = 89\% (95\% Cl: 69-97\%) respectively.

\section{DISCUSSION}

Diagnosing endometrial abnormalities is an important component of gynecological care. Endometrial imaging are forced to pursue cheap, simple diagnostic algorithms that may lead to proper diagnosis and further treatment. In 2010 the International Endometrial Tumor Analysis (IETA) group published a consensus on terms, definitions and measurements of sonographic features as a basis for prospective studies. They contain also the assessment of color and power Doppler sonography [8].

The benefits of transvaginal sonography with color Doppler, saline infusion sonohysterography and hystero- scopy are highly supported [8, 9]. Transvaginal sonography is a widely accepted method of endometrial evaluation and many authors believe that normal sonography endometrial imaging sufficiently establishes absence of pathology in perimenopausal patients with abnormal uterine bleeding [10-12].

Endometrial polyp diagnosis based on feeding artery visualization using color and power Doppler techniques is a relatively new method which has not yet been supported by many studies. In our study the presence of a feeding artery was found in 13 patients, 11 of whom had pathological confirmation of an endometrial polyp. Jakab et al. similarly found that feeding artery detection was $97 \%$ sensitive in diagnosing endometrial polyps [7]. There are also reports of using color Doppler to differentiate polyps from other endometrial abnormalities based on vascularization structure [13] Most endometrial polyps (81.3\%) have a single feeding artery, whereas other endometrial changes are characterized by dispersed vascularization, rarely detected finding in polyps [13]. In our study, pathologically confirmed endometrial polyps had a single feeding artery.

Our findings support others' conclusions that saline infusion sonohysterography enables superior imaging of uterine cavity abnormalities compared to classical transvaginal sonography. Our sensitivity of $75 \%$, specificity of $100 \%$, positive predictive value of $75 \%$, and negative predictive value of $72 \%$ for saline infusion sonohysterography in diagnosing endometrial polyps are similar to those reported by other authors [6, 14-17]. The procedure is also much better tolerated compared to hysteroscopy $[15,16]$. Some authors consider negative sonohysterography results to sufficiently rule out intrauterine abnormalities [6].

Several authors have reported findings that conflict with the present study. Poorer SIS sensitivity and specificity have been reported $[9,18,19]$. In the group of 105 patients sonohysteroscopy failed to detect endometrial polyps in 30 cases [18], SIS may also lead to erroneous diagnosis of blood clots as endometrial polyps [20]. Many authors do not regard sonohysterography results as sufficient evidence to confirm or exclude endometrial abnormalities [4, 6, 12, 21-24].

In our study, we aimed to determine whether combining classical transvaginal sonography with saline infusion into the uterine cavity plus feeding artery visualisation could be used as a screening test. We found that this diagnostic algorithm for endometrial polyps was associated with a sensitivity of $84 \%$, specificity of $95 \%$, positive predictive value of $96 \%$, and negative predictive value of $89 \%$.

\section{CONCLUSIONS}

Saline infusion sonohysterography combined with feeding artery visualization in transvaginal sonography is an interesting tool for diagnostics of endometrial polyps 
in perimenopausal women. Despite small study group this method showed promising results in our study and would probably be a very useful tool in the future.

\section{REFERENCES}

1. Salim $\mathrm{S}$, Won $\mathrm{H}$, Nesbitt-Hawes $\mathrm{E}$, et al. Diagnosis and management of endometrial polyps: a critical review of the literature. J Minim Invasive Gynecol. 2011; 18(5):569-581, doi: 10.1016/j.jmig.2011.05.018, indexed in Pubmed: 21783430.

2. Indraccolo U, Di lorio R, Matteo M, et al. The pathogenesis of endometrial polyps: a systematic semi-quantitative review. Eur J Gynaecol Oncol. 2013; 34(1): 5-22, indexed in Pubmed: 23589993.

3. Lee SC, Kaunitz AM, Sanchez-Ramos L, et al. The oncogenic potential of endometrial polyps: a systematic review and meta-analysis. Obstet Gynecol. 2010; 116(5): 1197-1205, doi: 10.1097/AOG.0b013e3181f74864, indexed in Pubmed: 20966706.

4. Litta P, Di Giuseppe J, Moriconi L, et al. Predictors of malignancy in endometrial polyps: a multi-institutional cohort study. Eur J Gynaecol Oncol. 2014; 35(4): 382-386, indexed in Pubmed: 25118478.

5. Wheeler KC, Goldstein SR. Transvaginal Ultrasound for the Diagnosis of Abnormal Uterine Bleeding. Clin Obstet Gynecol. 2017; 60(1): 11-17, doi: 10.1097/GRF.0000000000000257, indexed in Pubmed: 28005589.

6. de Kroon CD, de Bock GH, Dieben SWM, et al. Saline contrast hysterosonography in abnormal uterine bleeding: a systematic review and meta-analysis. BJOG. 2003; 110(10): 938-947, indexed in Pubmed: 14550365.

7. Jakab A, Ovári L, Juhász B, et al. Detection of feeding artery improves the ultrasound diagnosis of endometrial polyps in asymptomatic patients. Eur J Obstet Gynecol Reprod Biol. 2005; 119(1): 103-107, doi: 10.1016/j.ejogrb.2004.06.044, indexed in Pubmed: 15734093.

8. Leone FPG, Timmerman D, Bourne T, et al. Terms, definitions and measurements to describe the sonographic features of the endometrium and intrauterine lesions: a consensus opinion from the International Endometrial Tumor Analysis (IETA) group. Ultrasound Obstet Gynecol. 2010; 35(1): 103-112, doi: 10.1002/uog.7487, indexed in Pubmed: 20014360.

9. Bingol B, Gunenc Z, Gedikbasi A, et al. Comparison of diagnostic accuracy of saline infusion sonohysterography, transvaginal sonography and hysteroscopy. J Obstet Gynaecol. 2011; 31(1): 54-58, doi: 10.3109/014 43615.2010.532246, indexed in Pubmed: 21280995.

10. Opolskiene G, Sladkevicius $P$, Jokubkiene L, et al. Three-dimensional ultrasound imaging for discrimination between benign and malignant endometrium in women with postmenopausal bleeding and sonographic endometrial thickness of at least $4.5 \mathrm{~mm}$. Ultrasound Obstet Gynecol. 2010; 35(1): 94-102, doi: 10.1002/uog.7445, indexed in Pubmed: 19902471.

11. Jokubkiene $L$, Sladkevicius $P$, Valentin $L$. Transvaginal ultrasound examination of the endometrium in postmenopausal women without vaginal bleeding. Ultrasound Obstet Gynecol. 2016; 48(3): 390-396, doi: 10.1002/uog.15841, indexed in Pubmed: 26678251.

12. Wong ASW, Lao TTH, Cheung CW, et al. Reappraisal of endometrial thickness for the detection of endometrial cancer in postmenopausal bleeding: a retrospective cohort study. BJOG. 2016; 123(3): 439-446, doi: 10.1111/1471-0528.13342, indexed in Pubmed: 25800522.

13. Cil AP, Tulunay G, Kose MF, et al. Power Doppler properties of endometrial polyps and submucosal fibroids: a preliminary observational study in women with known intracavitary lesions. Ultrasound Obstet Gynecol. 2010; 35(2): 233-237, doi: 10.1002/uog.7470, indexed in Pubmed: 20101638.

14. Tamanaha S, Aldrighi JM, Santos RE, et al. [Sensitivity and specificity of hysterosonography in endometrial abnormalities in asymptomatic postmenopausal women]. Rev Assoc Med Bras (1992). 2004; 50(4): 427-432, doi: /S0104-42302004000400035, indexed in Pubmed: 15666026.

15. Choudry A, Shukr I, Khan S, et al. Acceptability and accuracy of saline infusion sonohysterography in women with postmenopausal bleeding. J Coll Physicians Surg Pak. 2010; 20(9): 571-575, doi: 09.2010/JCPSP.571575, indexed in Pubmed: 20810046.

16. Gumus II, Keskin EA, Kiliç E, et al. Diagnostic value of hysteroscopy and hysterosonography in endometrial abnormalities in asymptomatic postmenopausal women. Arch Gynecol Obstet. 2008; 278(3): 241-244, doi: 10.1007/s00404-008-0560-4, indexed in Pubmed: 18214508.

17. Vathanan V, Armar NA. A Comparative Observational Study of the Use of Saline Uterine Hydrosonography for the Diagnosis and Assessment of Uterine Cavity Lesions in Women. Int J Reprod Med. 2016; 2016: 9317194, doi: 10.1155/2016/9317194, indexed in Pubmed: 27597989.

18. Metzger U, Bernard JP, Camatte S, et al. Sono-guided endometrial biopsy: comparison with hysteroscopy biopsy. Sono-guided endometrial biopsy using the Bernard catheter had no impact on endometrial assessment by sonohysterography. Gynecol Obstet Invest. 2004; 58(1): 26-31, doi: 10.1159/000077393, indexed in Pubmed: 15031622.

19. Ogutcuoglu B, Karadag C, Inan C, et al. Diagnostic utility of saline infusion doppler sonohysterography in endometrial mass lesions. Pak J Med Sci. 2016; 32(2): 284-288, doi: 10.12669/pjms.322.9452, indexed in Pubmed: 27182224.

20. Semczuk A, Skorupski P, Olcha P, et al. Giant uterine leiomyomas causing bilateral hydronephrosis coexisting with endometrial cancer in polyp: a case study. Eur J Gynaecol Oncol. 2009; 30(3): 344-346, indexed in Pubmed: 19697639.

21. Braun MM, Overbeek-Wager EA, Grumbo RJ. Diagnosis and Management of Endometrial Cancer. Am Fam Physician. 2016; 93(6): 468-474, indexed in Pubmed: 26977831.

22. Epstein E, Van Holsbeke C, Mascilini F, et al. Gray-scale and color Doppler ultrasound characteristics of endometrial cancer in relation to stage, grade and tumor size. Ultrasound Obstet Gynecol. 2011;38(5): 586-593, doi: 10.1002/uog.9038, indexed in Pubmed: 21547974.

23. Bartkowiak R, Kaminski $P$, Wielgos $M$, et al. [Accuracy of transvaginal sonography, sonohysterography and hysteroscopy in diagnosis of intrauterine pathology]. Ginekol Pol. 2003; 74(3): 203-209, indexed in Pubmed: 12916257.

24. Stachowiak G, Zając A, Pertynska-Marczewska M, et al. 2D/3D ultrasonography for endometrial evaluation in a cohort of 118 postmenopausal women with abnormal uterine bleedings. Ginekol Pol. 2016; 87(12): 787-792, doi: 10.5603/GP.2016.0089, indexed in Pubmed: 28098928. 